\title{
IDENTIFICATION OF BACILLUS ANTHRACIS BY API TESTS
}

\author{
N. A. Logan*, J. A. Carman $\dagger$, J. Melling† and R. C. W. Berkeley \\ Department of Microbiology, The Medical School, University Walk, Bristol BS8 ITD, \\ and $\dagger$ Centre for Applied Microbiology and Research, Porton Down, Salisbury, Wiltshire \\ SP4 OJG
}

\begin{abstract}
SUMMARY. API and morphological tests were examined for their ability to distinguish between 37 Bacillus anthracis strains (virulent and avirulent) and 194 strains of closely related Bacillus species (B. cereus, B. mycoides and $B$. thuringiensis). In addition, 34 strains of $B$. anthracis and four of $B$. cereus were tested by several other methods that included capsule formation, ability to grow on a selective medium, and sensitivity to phage. It was found that virulent strains of $B$. anthracis were easily separated from the closely related Bacillus species by most of the test methods; but separation of slightly virulent and avirulent strains of $B$. anthracis from the closely related species could be done only by API and phage-sensitivity tests.
\end{abstract}

\section{INTRODUCTION}

The recognition of typical virulent strains of Bacillus anthracis isolated from clinical material is a comparatively simple problem (Sterne, 1967), but the identification of strains from non-clinical material may not be so easy (Burdon, 1956; Biegeleissen et al., 1962; Knisely, 1965; Wilson and Miles, 1975; Clarke et al., 1977). Furthermore, the possibility that atypical, slightly virulent or avirulent strains of $B$. anthracis may be present in a specimen should always be borne in mind.

Because of the considerable similarity between B. anthracis and B. cereus, many techniques for the selective isolation (Pearce and Powell, 1951; Morris, 1955; Green and Jamieson, 1958; Knisely, 1965 and 1966) and identification (Brown and Cherry, 1955; Chadwick, 1959 and 1963; Bonventre and Eckert, 1963) of B. anthracis have been developed, but none is absolutely reliable. $B$. cereus, although often regarded as a laboratory contaminant, is now recognised as a pathogen and isolated as such with increasing frequency (Turnbull et al., 1979; Gilbert et al., 1981).

It is not usually difficult to separate virulent strains of $B$. anthracis from $B$. cereus, but the relationship between avirulent $B$. anthracis strains and $B$. cereus, about which there has been argument for many years, remains unclear.

In this paper, we show that avirulent and slightly virulent strains of $B$. anthracis

Received 28 Sep. 1984; accepted 26 Nov. 1984.

* Present address: Department of Biological Sciences, Glasgow College of Technology, Cowcaddens Road, Glasgow G4 OBA. 
give the biochemical reactions of typical B. anthracis strains in API tests and are easily separated from other members of the $B$. cereus group on this basis.

\section{Materials AND Methods}

Organisms. The 37 B. anthracis strains studied are listed in table I. B. cereus strains were isolated from soil (4 strains), Pitch Lake, Trinidad (1), food and milk (2), uncooked rice (7), custard pie (1), food poisoning outbreaks, commonly diarrhoeal types (10), brain abscess (1), artificial hip joints (2), burn (1), blood (2), wounds (8), other infections (22), bovine source (1), pig (1), rat (1), anticorrosion coating (1), unspecified sources (12); one was the $B$. cereus "type strain" and others were received as B. albolactis (4), B. anthracoides (1), and B. fluorescens (3). Thirty further strains of $B$. cereus, including those isolated from outbreaks of emetic-type food poisoning (see Taylor and Gilbert, 1975; Gilbert and Parry, 1977), belonged to serotypes 1 (14 strains), 3 (6), 5 (4), $8(5)$ and 12 (1); 11 of these strains had been demonstrated to possess emetic activity (Logan et al., 1979). Four additional strains of $B$. cereus were freshly isolated from soil from Gruinard Island, which was contaminated with spores of the type strain of B. anthracis in the 1940s (see Manchee et al., 1981). B. mycoides strains were isolated from soil (5 strains), dust (1), sheep faeces (1), grass (1), milk (1), cheese (1), and unspecified sources (12); a further three were received as $B$. praussnitzi. Fifty-three $B$. thuringiensis strains were of serotypes 1 (4 strains), 2(5), 3a (5), 3ab (3), 4ab (6), 4ac (1), 5ab (2), 6(4), 7(2), 8 (1), 9(2), $10(2), 11(1), 12(1), 13(1), 14$ (4), and unknown (9).

Spore suspensions for virulence tests. Strains were grown on Nutrient Agar (Oxoid), containing $\mathrm{MnSO}_{4} \cdot \mathrm{H}_{2} \mathrm{O} 5 \mathrm{mg} / \mathrm{L}$ to promote rapid sporulation (Claus and Schaab-Engels, 1977) in Roux bottles for $48 \mathrm{~h}$ at $37^{\circ} \mathrm{C}$. Sporulation was monitored by the microscopical examination of films. Spores were washed off the medium with water, heated at $60^{\circ} \mathrm{C}$ for $90 \mathrm{~min}$, and viable counts were made. Viable counts were accurate to within $\pm 10 \%$; and in any one set of dilutions for inoculation, the ten-fold differences between dilutions were accurate to within $\pm 5 \%$. Dilutions, made in water because saline caused aggregation of spores, gave final counts in the range from 8 to $10^{6}$ spores in $0 \cdot 1 \mathrm{ml}$.

Virulence tests. Mice weighing 18-22 g were distributed in groups of ten, five to a cage. Each mouse was given $0.1 \mathrm{ml}$ of a spore suspension intraperitoneally. Each set of tests included 10 mice given $10^{3}$ spores of strain BO463 (Vollum; type strain) as the positive control. Mice were held for 6 days, inspected frequently, and deaths counted each day. There was no evidence that the few incidents of cannibalism affected the results.

Morphological tests. Strains of all species except B. anthracis were grown overnight at $30^{\circ} \mathrm{C}$ on plates of Nutrient Agar (Difco) containing $\mathrm{MnSO}_{4} \cdot \mathrm{H}_{2} \mathrm{O} 5 \mathrm{mg} / \mathrm{L}$ and examined in saline suspension smears by phase contrast microscopy at $\times 1000$ magnification for the presence of chains of cells, vacuoles, and motility. Cell widths were measured with an AEI Image-Splitting Eyepiece (Vickers Instruments, Haxby Road, York); this is more accurate than an eyepiece graticule (Quesnel, 1971; Logan, 1980; Logan and Berkeley, 1981). Lack of motility was confirmed by observing cells in water of condensation taken from nutrient-agar slopes incubated at $30^{\circ} \mathrm{C}$ for $6 \mathrm{~h}$ or until growth appeared thereafter. For the observation of sporangial morphology, plates were reincubated until spores appeared. Smears were examined for spore shapes and positions, swelling of sporangia, and the presence of crystalline inclusions (see Logan, 1980).

B. anthracis strains were grown on Brain Heart Infusion Agar (Oxoid) in Roux bottles overnight at $30^{\circ} \mathrm{C}$ in sealed transfer containers and growth was washed off with sterile normal saline. The washings were used for the preparation of API inocula and for morphological studies. For the latter purpose dense suspensions in normal saline were treated with formaldehyde $1 \% \mathrm{v} / \mathrm{v}$ overnight so that examinations could be made on killed organisms without the use of the safety cabinets in which all studies with live $B$. anthracis strains were made. Less than $5 \%$ of the organisms had sporulated. This was sufficient for the observations on sporangia to be made but not enough to affect adversely the use of the API strip inocula. Motility was detected as diffuse growth around the line of stab inoculation in tubes of motility medium (Cowan, 1974). Single strains of B. cereus, B. mycoides and B. thuringiensis were used as controls for all studies on B. anthracis. 
API tests. B. cereus, B. mycoides and B. thuringiensis were grown as lawns on plates of Nutrient Agar overnight at $30^{\circ} \mathrm{C}$. B. anthracis and control strains of B. cereus, B. mycoides and B. thuringiensis were grown on Brain Heart Infusion Agar in Roux bottles overnight at $30^{\circ} \mathrm{C}$. Cells were harvested in sterile normal saline and suspensions prepared, to the opacity of McFarland's (1907) standard tube no. 3 (15 International Opacity Units, OD 0.65 at $450 \mathrm{~nm}$ ), in 5 -ml volumes of saline and in 10-ml volumes of API 50CHE medium (API Laboratory Products Ltd, Grafton Way, Basingstoke, Hampshire) for the API 20E strip and the API 50CH gallery respectively. The first 12 tests of the $20 \mathrm{E}$ strip and all the tubes of the $50 \mathrm{CH}$ gallery were inoculated according to the manufacturer's instructions, but the tubes of the $50 \mathrm{CH}$ gallery were not sealed with mineral oil. Strips and galleries were incubated at $30^{\circ} \mathrm{C}$, and readings were made at 24 and $48 \mathrm{~h}$. Reagents for the tryptophan deaminase, indole, VP, and nitrate reduction tests of the API 20E strip were added at the time of the second reading. Roux bottles and API strips and galleries containing $B$. anthracis and control strains were incubated in sealed transfer containers for safety.

Results were scored from 0 (negative) to 5 (strong positive) for computer analyses as described by Logan (1980) and Logan and Berkeley (1981). For the preparation of tables of percent positive results, scores of 3 and above were regarded as positive.

Details of the development of an API identification scheme for Bacillus species are given by Logan (1980), Logan and Berkeley (1981) and Berkeley et al. (1984).

Bicarbonate agar test. Strains were grown on plates of Nutrient Agar (Oxoid) containing sodium bicarbonate $0.5 \% \mathrm{w} / \mathrm{v}$ and horse serum $5 \%$ in an atmosphere containing $\mathrm{CO}_{2} c .60 \%$ at $37^{\circ} \mathrm{C}$ for $24 \mathrm{~h}$. After incubation they were examined for mucoid growth.

$M^{\prime}$ Fadyean reaction. Strains were incubated in defibrinated horse blood for $8 \mathrm{~h}$ at $37^{\circ} \mathrm{C}$. Smears were then made, gently heat-fixed, stained with polychrome methylene blue (Gurr, BDH Chemicals Ltd, Broom Road, Poole, Dorset) and examined at $\times 1000$ magnification for blue rods surrounded by capsular material stained purplish pink.

Colonial texture test. Colonies on plates of Nutrient Agar (Oxoid) incubated at $37^{\circ} \mathrm{C}$ for $24 \mathrm{~h}$ were teased with an inoculating loop and observed for the characteristic tenacity of $B$. anthracis colonies or the butyrous texture of $B$. cereus colonies.

Growth on the selective medium of Knisely (1966). Strains were inoculated on to plates of PLET agar (Heart Infusion Agar, Difco, containing polymyxin 30 units $/ \mathrm{ml}$, lysozyme $40 \mu \mathrm{g} / \mathrm{ml}$, disodium ethylenediaminetetraacetate $300 \mu \mathrm{g} / \mathrm{ml}$ and thallous acetate $40 \mu \mathrm{g} / \mathrm{ml}$ ) and incubated at $37^{\circ} \mathrm{C}$ for $24 \mathrm{~h}$. This medium allows the recovery of $B$. anthracis strains but inhibits the growth of most $B$. cereus strains and most other Bacillus species.

Sensitivity to phage. Lawns of the strains were prepared on plates of Nutrient Agar (Oxoid) by spread inoculating with $0.1 \mathrm{ml}$ of an overnight broth culture. One loopful of $\gamma$-phage (Brown and Cherry, 1955) suspension containing $10^{7}$ plaque-forming units $/ \mathrm{ml}$ was placed in the centre of the plate. Inocula were allowed to dry and plates were incubated at $37^{\circ} \mathrm{C}$ for $18 \mathrm{~h}$ and examined for areas devoid of growth.

\section{RESULTS}

\section{Virulence tests}

Table II shows that the $B$. anthracis strains were broadly divisible into three groups-virulent, slightly virulent and avirulent. Where the histories of the strains were known, the results were as expected; thus the type strain (Vollum B0463) showed high virulence, the Sterne "avirulent" strain (B0464) low virulence, the two "teaching" or "class" strains (B0474, B0475) of the late Dr T. Gibson, low virulence; eleven recent isolates from anthrax outbreaks (B0477-BO482 and B1121-B1125) showed high virulence and three strains (B1117-B1119), received in response to a request for avirulent strains, low virulence. Five strains (B1126-B1128, B1130 and B1131) which were maintained on slopes between the 1920 s and the 1940s (R. E. Gordon personal communication) comprised two avirulent and three virulent strains. 
TABLE I

Strains of Bacillus anthracis

\begin{tabular}{|c|c|c|}
\hline Strain no. & Source and collection no. & Origin or Comment \\
\hline B0463 & NCTC 10340 & Vollum; from cow; type strain \\
\hline B0464 & NCTC 8234 & Spears, 34 F 2 (Sterne); avirulent \\
\hline B0467 & NCTC 2620 & Hankow; Chinese hide; Robertson, 1928 \\
\hline B0468 & NCTC 5444 & St Mary's; Fleming, 1938 \\
\hline B0469 & NCTC 1328 & Fildes, 1922 \\
\hline B0470 & NCTC 109 & Paddington VI; shaving brush, 1920 \\
\hline B0471 & Gibson 958 & Armitage \\
\hline B0472 & Gibson 961 & NCTC 2620 \\
\hline B0473 & Gibson 962 & Lister 4991 \\
\hline B0474 & Gibson 1010 & "Class" strain \\
\hline B0475 & Gibson 1011 & Soil culture of G1010 \\
\hline B0476 & Gibson 1012 & Cheyne \\
\hline B0477 & Wbrg A52-77 & Cattle \\
\hline B0478 & Wbrg A 73-77 & Groundnut meal \\
\hline B0479 & Wbrg A183-78 & Groundnut meal \\
\hline B0480 & Wbrg A187-78 & Cow, Devon \\
\hline B0481 & Wbrg A188-78 & Bovine source, Devon \\
\hline B0482 & Wbrg A191-78 & Dairy cow, Shropshire \\
\hline B0483 & CAMR B1 & Avirulent \\
\hline B0484 & CAMR M36 & Enhanced virulence for rabbits \\
\hline B1115 & CAMR M84 & Soil, Taunton \\
\hline B1116 & Wbrg A219-78 & Cow \\
\hline B1117 & Böhm 1 & Sterne strain \\
\hline B1118 & Böhm 2 & NP1/R protective antigen production \\
\hline B1119 & Böhm 15 & Vaccine strain, Roumania \\
\hline B1121 & Glfd C73 & Cerebro-spinal fluid, fatal case, 1974 \\
\hline B1122 & Glfd Cll1 & $\begin{array}{l}\text { Blood, fatal case, } 1974 \text {, penicillin } \\
\text { resistant }\end{array}$ \\
\hline B1123 & Glfd C149 & Skin lesion, 1976, from wool \\
\hline B1124 & Glfd Cl64 & Skin lesion, 1976, from hides \\
\hline B1125 & Glfd Cl65 & Skin lesion, 1976, infected animal \\
\hline B1126 & ATCC 240 & Jordan, NIH (NRS 1008I) \\
\hline B1127 & ATCC 937 & Eichorn 1 (NRS 1010) \\
\hline B1128 & ATCC 938 & Eichorn 2 (NRS 1011) \\
\hline B1129 & ATCC 10 & NIH, 152 (NRS 1007) \\
\hline B1130 & ATCC 241 & Jordan, NIH (NRS 1009) \\
\hline B1131 & ATCC 944 & Levine, 2025; creamery waste \\
\hline
\end{tabular}

Abbreviations and designations: ATCC, American Type Culture Collection strains from Dr R. E. Gordon, Rutgers University, New Brunswick, NJ, USA; Böhm, Dr R. Böhm, Universität Hohenheim, Stuttgart, West Germany; CAMR, Centre for Applied Microbiology and Research, Porton Down, Salisbury, Wiltshire; Eichorn, A. Eichorn, Lederle Laboratories, Pearl River, New York, USA; Gibson, from collection of the late Dr T. Gibson now held at the University of Bristol; Glfd, Dr J. R. Davies, Public Health Laboratory, Guildford, Surrey; Jordan, E. O. Jordan, University of Chicago, Chicago, IL, USA; Levine, M. Levine, Iowa State University, Ames, IO, USA; NCTC, National Collection of Type Cultures, Central Public Health Laboratory, Colindale, London; NIH, National Institutes of Health, Bethesda, MD, USA; NRS, N. R. Smith Collection, US Department of Agriculture, Washington DC, USA; Wbrg, Dr D. Spackman, Central Veterinary Laboratory, Weybridge, Surrey.

\section{Morphological and API tests}

The results of morphological and API tests for all the species studied, those for $\boldsymbol{B}$. anthracis classified according to virulence, are summarised in table III. The different species or groups showed close similarity. No test was specific for B. anthracis, and in only four tests-arginine dihydrolase (ADH), growth on Simmons' citrate medium and production of acid from glycerol and cellobiose- did B. anthracis alone give consistently negative results. 
TABLE II

Results of tests for virulence of $34 \mathrm{~B}$. anthracis strains in mice

\begin{tabular}{|c|c|c|c|c|c|c|c|c|c|}
\hline \multirow[b]{2}{*}{ Strain no. } & \multicolumn{8}{|c|}{$\begin{array}{l}\text { Total deaths in groups of } 10 \text { mice (days to reach total) } \\
\text { receiving the following doses of spores }\end{array}$} & \multirow[b]{2}{*}{ Virulence } \\
\hline & 8 & 40 & 100 & 200 & $10^{3}$ & $10^{4}$ & $10^{5}$ & $10^{6}$ & \\
\hline B0463 & $0(6)$ & $4(3)$ & $\cdots$ & $8(5)$ & $10(4)$ & & & & V \\
\hline B0464 & & . & & (-) & $0(6)$ & $2(6)$ & $3(4)$ & $6(4)$ & LV \\
\hline B0467 & $\ldots$ & $\ldots$ & $1(4)$ & $\ldots$ & $9(5)$ & $10(3)$ & $10(4)$ & $\ldots$ & V \\
\hline B 0469 & & $\ldots$ & 0 (6) & $\ldots$ & $0(6)$ & $0(6)$ & $0(6)$ & $\ldots$ & AV \\
\hline B0470 & $\ldots$ & $\ldots$ & $0(6)$ & $\ldots$ & $0(6)$ & $0(6)$ & $0(6)$ & $\ldots$ & AV \\
\hline B0471 & $\ldots$ & $\ldots$ & $5(4)$ & $\ldots$ & 7 (4) & $10(5)$ & $10(3)$ & $\ldots$ & V \\
\hline B0472 & $\ldots$ & $\ldots$ & $1(3)$ & $\ldots$ & $6(5)$ & $10(4)$ & $10(3)$ & $\ldots$ & V \\
\hline B0473 & $\cdots$ & $\ldots$ & $7(5)$ & $\ldots$ & $7(4)$ & $10(4)$ & $10(4)$ & $\ldots$ & V \\
\hline B0474 & $\ldots$ & $\ldots$ & $0(6)$ & $\ldots$ & $0(6)$ & $0(6)$ & $2(5)$ & $\ldots$ & LV \\
\hline B0475 & $\ldots$ & $\ldots$ & $0(6)$ & $\ldots$ & $0(6)$ & $1(4)$ & $1(6)$ & $\ldots$ & LV \\
\hline B0476 & $\ldots$ & $\ldots$ & $4(4)$ & $\ldots$ & $10(5)$ & $10(3)$ & $10(3)$ & $\ldots$ & V \\
\hline B0477 & $\ldots$ & $\ldots$ & $5(3)$ & $\ldots$ & $9(4)$ & $10(3)$ & $10(2)$ & $\ldots$ & V \\
\hline B0478 & $\ldots$ & $\ldots$ & $8(4)$ & $\ldots$ & $10(3)$ & 9 (4) & $10(2)$ & $\ldots$ & V \\
\hline B0479 & $\ldots$ & $\ldots$ & $7(4)$ & $\ldots$ & $10(4)$ & $10(2)$ & $10(2)$ & $\ldots$ & V \\
\hline B0480 & $\ldots$ & $\ldots$ & $9(4)$ & $\ldots$ & $10(3)$ & $10(2)$ & $10(2)$ & $\ldots$ & V \\
\hline B0481 & $\ldots$ & $\ldots$ & $8(6)$ & $\ldots$ & $10(4)$ & $10(2)$ & $10(2)$ & $\ldots$ & V \\
\hline B0482 & & $\ldots$ & $8(6)$ & $\ldots$ & $10(3)$ & $10(2)$ & $10(2)$ & $\ldots$ & V \\
\hline B0483 & & & $0(6)$ & & $0(6)$ & $0(6)$ & $0(6)$ & $\ldots$ & AV \\
\hline B0484 & $1(5)$ & $1(3)$ & & $4(5)$ & $8(4)$ & & & $\ldots$ & V \\
\hline B1115 & $\ldots$ & $\ldots$ & $7(4)$ & $\ldots$ & $8(4)$ & $10(3)$ & $10(3)$ & $\ldots$ & V \\
\hline B1117 & $\ldots$ & $\ldots$ & $0(6)$ & $\ldots$ & $0(6)$ & $3(6)$ & $0(6)$ & $\ldots$ & LV \\
\hline B 1118 & $\ldots$ & $\ldots$ & 0 (6) & $\ldots$ & $0(6)$ & $2(4)$ & $1(3)$ & $\ldots$ & LV \\
\hline B1119 & $\ldots$ & $\ldots$ & $0(6)$ & $\ldots$ & $2(5)$ & $1(4)$ & $1(3)$ & $\ldots$ & LV \\
\hline B1 120 & $\ldots$ & $\ldots$ & 7 (4) & $\ldots$ & $8(3)$ & $10(2)$ & $10(3)$ & $\ldots$ & V \\
\hline 1121 & $\ldots$ & $\ldots$ & $5(4)$ & $\ldots$ & $10(5)$ & $10(2)$ & $10(3)$ & $\ldots$ & V \\
\hline B1122 & $\ldots$ & $\ldots$ & $10(3)$ & $\ldots$ & $10(2)$ & $10(3)$ & $10(3)$ & $\ldots$ & V \\
\hline B1123 & $\ldots$ & $\ldots$ & 7 (4) & $\ldots$ & $8(4)$ & $10(2)$ & $10(2)$ & $\ldots$ & V \\
\hline B1 124 & $\ldots$ & $\ldots$ & $6(5)$ & $\ldots$ & $9(3)$ & $10(4)$ & $10(3)$ & $\ldots$ & V \\
\hline B1 125 & $\ldots$ & $\ldots$ & $5(6)$ & $\ldots$ & $9(4)$ & $10(4)$ & $10(3)$ & $\ldots$ & V \\
\hline B1126 & & $\ldots$ & $0(6)$ & $\ldots$ & $2(6)$ & $5(6)$ & $7(6)$ & $\ldots$ & V \\
\hline B 1127 & $\ldots$ & $\ldots$ & $0(6)$ & $\ldots$ & $2(5)$ & $4(3)$ & 9 (4) & $\ldots$ & V \\
\hline B1128 & $\ldots$ & $\ldots$ & $0(6)$ & $\ldots$ & $0(6)$ & $0(6)$ & $0(6)$ & $\ldots$ & AV \\
\hline & $\ldots$ & $\ldots$ & $0(6)$ & $\ldots$ & $0(6)$ & $0(6)$ & $0(6)$ & $\ldots$ & AV \\
\hline 131 & & & $2(4)$ & $\ldots$ & $1(2)$ & $10(3)$ & $9(3)$ & $\ldots$ & V \\
\hline
\end{tabular}

$\mathrm{V}=$ virulent $\mathrm{LV}=$ low virulence; $\mathrm{AV}=$ avirulent

Separation could be made, however, by taking into account general patterns of results rather than relying on the reactions of a few specific tests. Thus, $B$. anthracis strains commonly gave results different from those of other members of the $B$. cereus group in at least five of the tests (including the four listed above). The tests useful in separating $B$. anthracis from $B$. cereus were $\mathrm{ADH}$, Simmons' citrate, glycerol, salicin, cellobiose, and motility; from $B$. mycoides - which characteristically produces rhizoid growth on solid media-Simmons' citrate, glycerol, salicin and cellobiose; from $B$. thuringiensis ADH, Simmons' citrate, glycerol, salicin, cellobiose, motility and crystalline inclusions in sporangia; and from $B$. cereus strains of serotypes $1,3,5,8$ and 12 (headed $B$. cereus ' $E$ ' in table III) Simmons' citrate, glycerol, starch, glycogen and motility.

Table III shows that the avirulent and slightly virulent strains of $B$. anthracis had test patterns similar to those of the virulent strains and so were easily distinguished from other members of the $B$. cereus group. There was only one suggestion of a relation 
TABLE III

Results of API, morphological, and supplementary tests on Bacillus strains

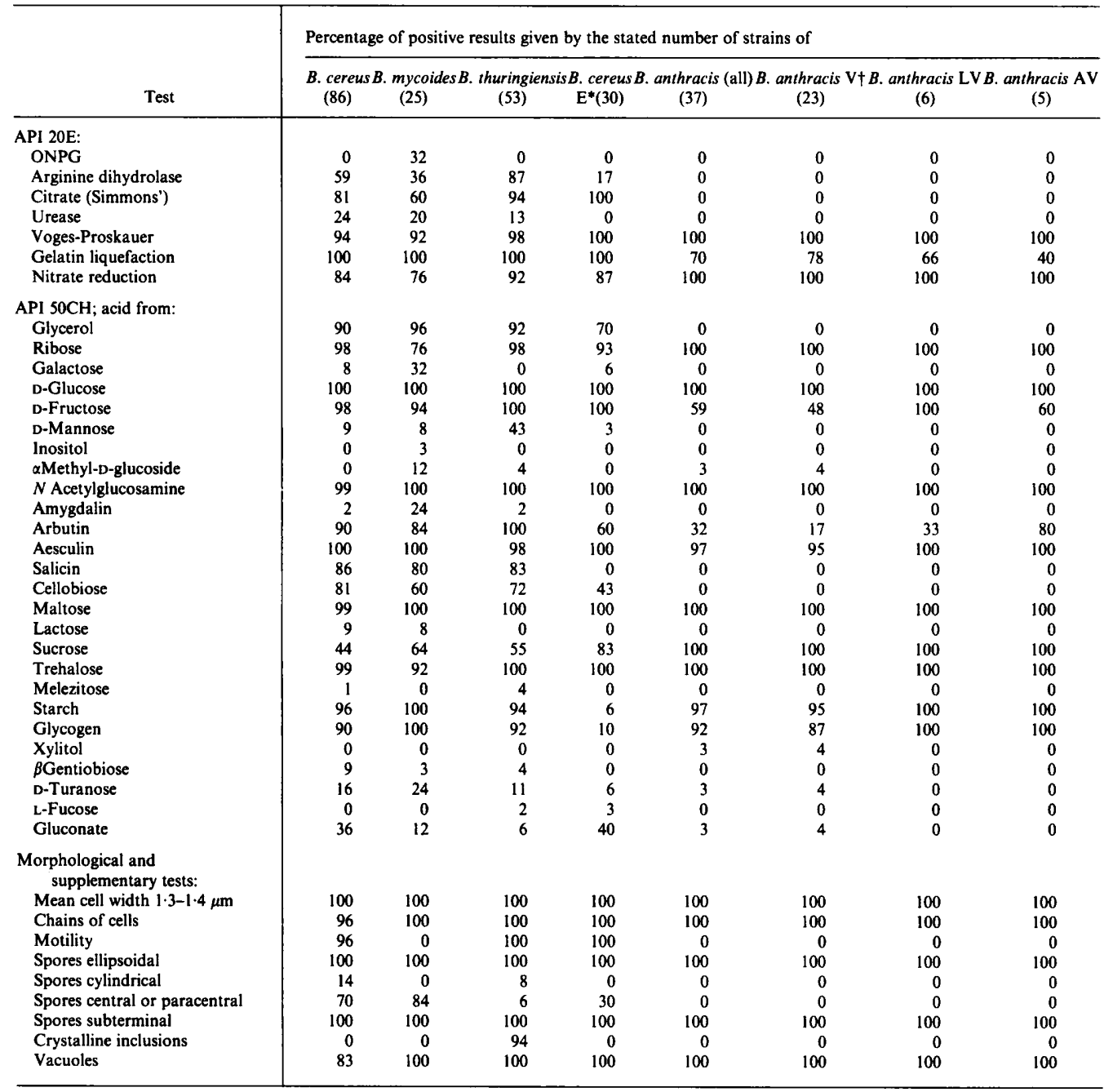

Tests in which all strains studied gave negative results were: API $20 \mathrm{E}$-lysine decarboxylase, ornithine decarboxylase, $\mathrm{H}_{2} \mathrm{~S}$ production, tryptophan deaminase, indole; API $50 \mathrm{CH}$ - erythritol, D-arabinose, L-arabinose, D-xylose, L-xylose, adonitol, $\beta$ methyl-xyloside, L-sorbose, rhamnose, dulcitol, mannitol, sorbitol, amethyl-D-mannoside, melibiose, inulin, D-raffinose, D-lyxose, D-tagatose, D-fucose, D-arabitol, L-arabitol, 2 keto-gluconate, 5 keto-gluconate; morphological and supplementary tests-spores round, spores terminal, sporangia swollen, parasporal bodies present, gas from carbohydrates.

$* B$. cereus strains of serotypes $1,3,5,8$ and 12 including those isolated from outbreaks of emetic-type food poisoning. $\dagger \mathrm{V}=$ virulent; $\mathrm{LV}=$ low virulence; $\mathrm{AV}=$ avirulent.

between virulence and test reaction: the proportion of arbutin positive reactions given by avirulent strains was higher $(80 \%)$ than that given by slightly virulent $(33 \%)$ and virulent strains (17\%). Many additional strains, however, gave weak reactions scored only as 1 and 2 and, therefore, excluded from the positive results (scored as 3 and above). Had they been included, the results would have been $80 \%, 83 \%$ and $43 \%$ respectively. These figures, taken with the small numbers of slightly virulent and avirulent strains, are not convincing. 
TABLE IV

Miscellaneous tests on 34 strains of $B$. anthracis

\begin{tabular}{|c|c|c|c|c|c|c|}
\hline \multirow[b]{2}{*}{ Strain no. } & \multirow[b]{2}{*}{ Virulence } & \multicolumn{5}{|c|}{ Results in the stated tests } \\
\hline & & $\begin{array}{c}\text { Mucoid colonies } \\
\text { on bicarbonate } \\
\text { agar }+\mathrm{CO}_{2}\end{array}$ & $\begin{array}{l}\text { M'Fadyean } \\
\text { reaction }\end{array}$ & $\begin{array}{c}\text { Texture of } \\
\text { colonies }\end{array}$ & $\begin{array}{c}\text { Growth } \\
\text { on PLET } \\
\text { agar }\end{array}$ & $\begin{array}{c}\text { Phage } \\
\text { sensitivity }\end{array}$ \\
\hline B0463 & $\mathrm{V}$ & $+\dagger$ & $(+) \ddagger$ & $T \S$ & $+\|$ & +9 \\
\hline B0464 & LV & - & - & $\mathrm{T}$ & + & $(+)$ \\
\hline B0467 & $\mathrm{V}$ & - & + & $\mathrm{T}$ & + & + \\
\hline B0469 & AV & - & - & $\mathrm{T} / \mathrm{B}$ & + & + \\
\hline B0470 & AV & + & - & $\mathrm{T}$ & + & $(+)$ \\
\hline B0471 & $\mathrm{V}$ & $(+)$ & + & $\mathrm{T}$ & + & + \\
\hline B0472 & $\mathrm{V}$ & - & - & $\mathrm{T}$ & + & + \\
\hline B0473 & $\mathrm{V}$ & + & - & $\mathrm{T}$ & + & + \\
\hline B0474 & LV & - & - & $\mathrm{T}$ & + & $(+)$ \\
\hline B0475 & LV & - & - & $\mathrm{T}$ & $(+)$ & + \\
\hline B0476 & $\mathrm{V}$ & + & + & $\mathrm{T}$ & + & $(+)$ \\
\hline B0477 & $\mathrm{V}$ & + & $(+)$ & $\mathrm{T}$ & + & + \\
\hline B0478 & $\mathrm{V}$ & $(+)$ & $(+)$ & $\mathrm{T}$ & + & $(+)$ \\
\hline B0479 & $\mathrm{V}$ & + & + & $\mathrm{T}$ & + & + \\
\hline B0480 & $\mathrm{V}$ & $(+)$ & $(+)$ & $\mathrm{T}$ & + & + \\
\hline B0481 & V & $(+)$ & $(+)$ & $\mathrm{T}$ & + & + \\
\hline B0482 & $\mathrm{V}$ & + & + & $\mathrm{T}$ & + & + \\
\hline B0483 & $\mathrm{AV}$ & - & - & $\mathrm{T}$ & + & + \\
\hline B0484 & $\mathrm{V}$ & + & $(+)$ & $\mathrm{T}$ & + & + \\
\hline B1115 & $\mathrm{V}$ & + & + & $\mathrm{T}$ & + & + \\
\hline B1117 & LV & - & - & $\mathrm{T} / \mathrm{B}$ & $(+)$ & + \\
\hline B1118 & LV & - & - & $\mathrm{T}$ & + & + \\
\hline B1119 & LV & - & - & $\mathrm{T}$ & $(+)$ & + \\
\hline B 1120 & $\mathrm{~V}$ & + & + & $\mathrm{T}$ & + & + \\
\hline B 1121 & v & + & $(+)$ & $\mathrm{T}$ & + & + \\
\hline B1122 & V & + & + & $\mathrm{T}$ & + & + \\
\hline B1123 & $\mathrm{V}$ & + & + & $\mathrm{T}$ & + & + \\
\hline B1124 & $\mathrm{V}$ & + & + & $\mathrm{T}$ & + & + \\
\hline B1125 & V & + & + & $\mathrm{T}$ & + & $( \pm)$ \\
\hline B1126 & $\mathrm{V}$ & + & - & $\mathrm{T} / \mathrm{B}$ & + & + \\
\hline B1127 & $\mathrm{v}$ & $\begin{array}{l}+ \\
+\end{array}$ & - & $\mathrm{T}$ & + & $\begin{array}{l}+ \\
+\end{array}$ \\
\hline B1128 & AV & - & - & $\mathrm{T} / \mathrm{B}$ & + & + \\
\hline B 1130 & AV & - & - & B & + & + \\
\hline B1131 & $\mathrm{V}$ & ++ & + & $T / B$ & + & + \\
\hline
\end{tabular}

See footnote to table II.

$+++=$ Very mucoid, $+=$ mucoid, $(+)=<30 \%$ of growth mucoid, $-=$ growth not mucoid

$\ddagger+=$ Obvious capsule, $(+)=$ capsulate organisms in minority, $-=$ non-capsulate.

$\S \mathrm{T}=$ tenacious, $\mathbf{T} / \mathrm{B}=$ intermediate, $\mathrm{B}=$ butyrous

$\|+=$ Growth, $(+)=$ growth only when inoculum heavy, $-=$ no growth.

$+=$ Clear plaque, $(+)=$ some growth across plaque, $( \pm)=$ plaque just visible, $-=$ no plaque

\section{Miscellaneous tests}

The formation of mucoid colonies, on a medium containing bicarbonate and serum and incubated in excess $\mathrm{CO}_{2}$, is characteristic of virulent strains of $B$. anthracis and indicates abundant capsule production. However, as can be seen from table IV, not all of our virulent strains produced mucoid colonies. Strains B0467 and B0472, which were shown to be virulent (table II), produced no mucoid growth; and strains B0471, B0478, B0480 and B0481, also virulent, produced colonies less than $30 \%$ of which were mucoid. All but one (B0470) of the avirulent strains and all of the slightly virulent strains, produced non-mucoid colonies. 
M'Fadyean's polychrome methylene blue will demonstrate $B$. anthracis capsules in fresh specimens or cultures grown in media that favour capsule production, such as blood. It can be seen from table IV that the results of the M'Fadyean reaction correlated less well with virulence than did the production of mucoid growth on bicarbonate agar in excess $\mathrm{CO}_{2}$. Four virulent strains (B0472, B0473, B1126 and B1127) did not produce capsules as demonstrated by the M'Fadyean reaction; only one of these (B0472) did not produce mucoid colonies on bicarbonate agar. One virulent non-mucoid strain (B0467) gave a positive M'Fadyean reaction, and all avirulent and low virulence strains gave negative reactions.

Strains of $\boldsymbol{B}$. anthracis cultivated on nutrient agar characteristically produce adherent colonies that show tenacity when disturbed with an inoculating loop; colonies of $B$. cereus have a butyrous texture. Most of the $B$. anthracis strains studied produced adherent colonies; two virulent strains (B1 126 and B1131), one strain of low virulence (B1117), and two avirulent strains (B0469 and B1128) produced adherent butyrous colonies and one avirulent strain (B1130) produced entirely butyrous colonies.

All of the B. anthracis strains grew on PLET medium; three strains (B0475, B1 117 and B1119), all of low virulence, grew only when a heavy inoculum was used. Knisely (1966) found that, on PLET medium, one of his strains grew poorly and only after incubation for $48 \mathrm{~h}$. In our hands, this strain, included in the present study as no. B1131, grew well on PLET medium.

All of the strains of $B$. anthracis were lysed by the $\gamma$-phage of Brown and Cherry (1955); five strains (B0464, B0470, B0474, B0476 and B0478) showed some growth across the plaques, and one strain (B1125) produced a plaque that was only just visible.

Four strains of $B$. cereus produced butyrous colonies on bicarbonate agar in excess $\mathrm{CO}_{2}$, gave negative M'Fadyean reactions, and lacked sensitivity to $\gamma$-phage. One strain produced small colonies on PLET agar and the others failed to grow.

\section{DisCUSSION}

It is generally accepted that loss of pathogenicity of $B$. anthracis occurs in culture (Smith et al., 1952). This phenomenon is referred to by Chu (1952), Burdon (1956), Ivánovics and Földes (1958), Leise et al. (1959) and Burdon and Wende (1960). It is interesting, however, that of 16 strains used in this study that had been held in culture collections for long periods before the introduction of lyophilisation for preservation (strains B0463, B0464, B0467, B0469-B0476, B1126-B1128, B1130 and B1131), only two (B0474 and B0475) showed low virulence and four (B0469, B0470, B1128 and B1130) were avirulent. The two low-virulence strains were Gibson's "teaching" or "class" strains, chosen with safety in mind; it is known that strain B1130 was avirulent when tested by Cowles (1931), and strain B1128 was found to be virulent by the same author. Only three strains (B0469, B0470 and B1128) out of 13 appear, therefore, to have lost their virulence, but no information is available on the histories and original virulence of these organisms. It is noteworthy that the remaining 10 strains showed high virulence and that the two "class" strains of Gibson retained their low virulence rather than having become avirulent. These last two, like the other Gibson strains (table I), were maintained on slopes, apparently without subculturing, since 1938; they grew overnight when subcultured in 1978.

Gordon et al. (1973) were of the opinion that it might be very difficult to distinguish 
between avirulent strains of $B$. anthracis and non-rhizoid variants of the usually non-motile $B$. mycoides. In the present work only four tests gave much assistance in making such a distinction. However, the fact that other tests which gave variable results for $B$. mycoides (ONPG, $\mathrm{ADH}$, urease, galactose, amygdalin, and D-turanose) were nearly always negative for $B$. anthracis gave the opportunity of making the distinction on the basis of reaction pattern.

API and morphological tests clearly separated 22 of the B. anthracis strains considered in this paper (B0463-B0484) from other members of the B. cereus group in the computer taxonomies of Logan (1980) and Logan and Berkeley (1981). The virulent, slightly virulent and avirulent strains of $B$. anthracis were not separable by these methods.

It has been seen that virulent strains of $B$. anthracis can be easily separated from $B$. cereus by the miscellaneous tests and the API and morphological tests. The separation of avirulent and slightly virulent strains of $B$. anthracis from $B$. cereus by the miscellaneous tests is not so easy because they may produce non-mucoid colonies on bicarbonate agar incubated in excess $\mathrm{CO}_{2}$, give negative M'Fadyean reactions, produce butyrous colonies on nutrient agar, and show poor growth on PLET medium-a medium upon which certain $B$. cereus strains can grow. The only tests in the present study which enabled such non-mucoid avirulent strains of $B$. anthracis to be separated from $B$. cereus were sensitivity to $\gamma$-phage-to which some strains of other Bacillus species, but not all strains of $B$. anthracis (Wilson and Miles, 1975), are susceptible - five API reactions, and motility - not always positive for $B$. cereus and always negative for $B$. mycoides.

It is apparent that a satisfactory identification system with a dichotomous key could not be based upon the tests described above, but clearly a comparison of the reaction pattern of an unidentified strain with the results presented in table III, with or without the aid of a computer (see Logan and Berkeley, 1984), would give an identification with a high probability of accuracy. Although all the members of the $B$. cereus group are very closely related it is clear that virulent, slightly virulent and avirulent strains of $B$. anthracis can easily be separated from other members of the group by the API tests described.

We thank all those who donated strains for study, API Laboratory Products Ltd for providing API test materials, Mrs Elaine Marchant for technical assistance, and Miss Kim McMillan for typing the manuscript.

\section{REFERENCES}

Berkeley R C W, Logan N A, Shute L A, Capey A G 1984 Identification of Bacillus species. In: Bergan T (ed) Methods in microbiology vol 16. Academic Press, London, pp 291-328.

Biegeleissen J Z, Cherry W B, Skaliy P, Moody M D 1962 The demonstration of Bacillus anthracis in environmental specimens by conventional and fluorescent antibody techniques. American Journal of Hygiene 75:230-239.

Bonventre P F, Eckert N J 1963 Toxin production as a criterion for differentiating Bacillus cereus and Bacillus anthracis. Journal of Bacteriology 85:490-491.

Brown E R, Cherry W B 1955 Specific identification of Bacillus anthracis by means of a variant bacteriophage. Journal of Infectious Diseases 96:34-39.

Burdon K L 1956 Useful criteria for the identification of Bacillus anthracis and related species. Journal of Bacteriology 71:25-42. 
Burdon K L, Wende R D 1960 On the differentiation of anthrax bacilli from Bacillus cereus. Journal of Infectious Diseases 107:224-234.

Chadwick P 1959 Rapid identification of Bacillus anthracis by microscopical observation of bacteriophage lysis. Journal of General Microbiology 21:631-634.

Chadwick P 1963 Rapid screening test for Bacillus anthracis. Canadian Journal of Microbiology 9:734-737.

Chu H P 1952 Variation of Bacillus anthracis with special reference to the non-capsulated avirulent variant. Journal of Hygiene 50:433-444.

Clarke H E, Coates M E, Eva J K, Ford D J, Milner C K, O'Donoghue P N, Scott P P, Ward R J 1977 Dietary standards for laboratory animals: report of the Laboratory Animals Centre Diets Advisory Committee. Laboratory Animals 11:1-28.

Claus D, Schaab-Engels C (eds) 1977 Catalogue of strains 2nd edn. Deutsche Sammlung von Microorganismen, München, $\mathrm{p} 276$.

Cowan S T 1974 Cowan and Steel's Manual for the identification of medical bacteria 2nd edn. Cambridge University Press, Cambridge, p 152.

Cowles P B 1931 A bacteriophage for B. anthracis. Journal of Bacteriology 21:161-166.

Gilbert R J, Parry J M 1977 Serotypes of Bacillus cereus from outbreaks of food poisoning and from routine foods. Journal of Hygiene 78:69-74.

Gilbert R J, Turnbull P C B, Parry J M, Kramer J M 1981 Bacillus cereus and other Bacillus species: their part in food poisoning and other clinical infections. In: Berkeley $\mathrm{R} \mathrm{C} \mathrm{W}$, Goodfellow M (eds) The aerobic endospore-forming bacteria: classification and identification. Academic Press, London, pp 297-314.

Gordon R E, Haynes W C, Pang C H-N 1973 The genus Bacillus. Agriculture handbook No. 427, United States Department of Agriculture. Washington D.C., pp 31-33.

Green D M, Jamieson W M 1958 Anthrax and bone-meal fertiliser. Lancet 2:153-154.

Ivánovics G, Földes J 1958 Problems concerning the phylogenesis of Bacillus anthracis. Acta Microbiologica Academiae Scientiarum Hungaricae 5:89-109.

Knisely R F 1965 Differential media for the identification of Bacillus anthracis. Journal of Bacteriology 90:1778-1783.

Knisely R F 1966 Selective medium for Bacillus anthracis. Journal of Bacteriology 92:784-786.

Leise J M, Carter C H, Friedlander H, Freed S W 1959 Criteria for the identification of Bacillus anthracis. Journal of Bacteriology 77:655-660.

Logan N A 1980 Studies on the taxonomy and identification of members of the genus Bacillus: application of miniaturized, standardized, commercially available test systems. $\mathrm{PhD}$ thesis, University of Bristol.

Logan N A, Berkeley R C W 1981 Classification and identification of members of the genus Bacillus using API tests. In: Berkeley $\mathbf{R} \mathbf{C ~ W}$, Goodfellow $\mathbf{M}$ (eds) The aerobic endospore-forming bacteria: classification and identification. Academic Press, London, pp $105-140$.

Logan N A, Berkeley R C W 1984 Identification of Bacillus strains using the API System. Journal of General Microbiology 130:1871-1882.

Logan N A, Capel B J, Melling J, Berkeley R C W 1979 Distinction between emetic and other strains of Bacillus cereus using the API System and numerical methods. FEMS Microbiology Letters 5:373-375.

McFarland J 1907 The nephelometer: an instrument for estimating the number of bacteria in suspensions used for calculating the opsonic index and for vaccines. Journal of the American Medical Association 49: 1176-1178.

Manchee R J, Broster M G, Melling J, Henstridge R M, Stagg A J 1981 Bacillus anthracis on Gruinard Island. Nature 294:254-255.

Morris E J 1955 A selective medium for Bacillus anthracis. Journal of General Microbiology 13: 456-460.

Pearce T W, Powell E O 1951 A selective medium for Bacillus anthracis. Journal of General Microbiology 5:387-390.

Quesnel L B 1971 Microscopy and micrometry. In: Norris J R, Ribbons D W (eds) Methods in microbiology, vol 5A, Academic Press, London, p 93.

Smith N R, Gordon R E, Clark F E 1952 Aerobic spore-forming bacteria. Agriculture monograph No. 16. United States Department of Agriculture, Washington D.C., p 66. 
Sterne M 1967 Distribution and economic importance of anthrax. Federation Proceedings 26:1493-1495.

Taylor A J, Gilbert R J 1975 Bacillus cereus food poisoning: a provisional serotyping scheme. Journal of Medical Microbiology 8:543-550.

Turnbull P C B, Jørgensen K, Kramer J M, Gilbert R J, Parry J M 1979 Severe clinical conditions associated with Bacillus cereus and the apparent involvement of exotoxins. Journal of Clinical Pathology 32:289-293.

Wilson G S, Miles A A (eds) 1975 Topley and Wilson's Principles of bacteriology, virology and immunity, 6 edn. Edward Arnold, London, vol 1 pp 1092-1093, vol 2 pp 2215-2216. 